Tropical Journal of Pharmaceutical Research June 2016; 15 (6): 1275-1281

ISSN: $1596-5996$ (print); 1596-9827 (electronic) (C) Pharmacotherapy Group, Faculty of Pharmacy, University of Benin, Benin City, 300001 Nigeria.

All rights reserved.

\title{
Determination of acrylamide levels in selected commercial and traditional foods in Syria
}

\author{
Hala Ayman Alyousef ${ }^{1,2,3}$, Hongxin Wang ${ }^{1,2 *}$, Nabil Qaid M Al-Hajj ${ }^{1,2}$ and Marwa \\ YF Koko ${ }^{1,2}$ \\ ${ }^{1}$ State Key Laboratory of Food Science and Technology, ${ }^{2}$ School of Food Science and Technology, Jiangnan University, Wuxi \\ 214122, PR China, ${ }^{3}$ Faculty of Health Science, Albaath University, Homs, Syria
}

*For correspondence: Email: hxwang@jiangnan.edu.cn; Tel: +8651085917795; Fax: +8651085876799

Received: 23 January 2016

Revised accepted: 28 April 2016

\begin{abstract}
Purpose: To determine acrylamide (AA) levels in different brands of commercial and traditional foodstuffs available in Syria by ultra-performance liquid chromatography-mass spectrometery (UPLCMS).

Methods: A total of 63 samples were analyzed. Food samples were defatted by hexane and then extracted with methanol $98 \%$ in a vortex mixer. Thereafter, Carrez I and Carrez II were added to precipitate proteins from the co-extractives and then centrifuged to obtain a clear aqueous extract that was evaporated to dryness. The extract was dissolved in $1 \mathrm{~mL}$ of water, eluted through a preconditioned Oasis HLB cartridge and then filtered. The filtrate was analyzed by UPLC-MS/MS to determine AA content.

Results: Among the commercial foods tested, the highest acrylamide quantity was found in potato products $\left(396 \pm 3.59-1844 \pm 5.29 \mu \mathrm{g} \mathrm{kg}^{-1}\right)$ and the lowest in corn products $(183 \pm 2.64-366 \pm 4.58$ $\left.\mu \mathrm{g} \mathrm{kg}^{-1}\right)$. This was followed by biscuits $\left(57 \pm 2.64-1433 \pm 2.51 \mu \mathrm{g} \mathrm{kg}^{-1}\right)$, breakfast cereals $(121 \pm 8.73$ $\left.-245 \pm 3.60 \mu \mathrm{g} \mathrm{kg}^{-1}\right)$, bread $\left(119 \pm 1.73-263 \pm 3.60 \mu \mathrm{g} \mathrm{kg}^{-1}\right)$ and then coffee $(113 \pm 2.64-64 \pm 3.05$ $\left.\mu \mathrm{g} \mathrm{kg}^{-1}\right)$. Regarding traditional foods, the highest level of $A A$ was found in AL-Mshabak (481 $\pm 2.08 \mu \mathrm{g}$ $\left.\mathrm{kg}^{-1}\right)$ and $A L-A$ wamat $\left(421 \pm 2.64 \mu \mathrm{gg}^{-1}\right)$ followed by AL-Namora (282 $\left.\pm 4.35 \mu \mathrm{g} \mathrm{kg}^{-1}\right)$ and $A L-K e n a f a$ $\left(242 \pm 2.64 \mu \mathrm{g} \mathrm{kg}^{-1}\right)$. It was also observed that the lowest amount of $A A$ was in fried bread (230 $\mu \mathrm{g}$ $\left.\mathrm{kg}^{-1}\right)$, AL-Fatayer $\left(192 \pm 3.51 \mu \mathrm{g} \mathrm{kg}^{-1}\right)$ and AL-Baqlawa $\left(172 \pm 4.35 \mu \mathrm{g} \mathrm{kg}^{-1}\right)$ while Eid Aqras (130 \pm 4.58 $\left.\mu \mathrm{g} \mathrm{kg}{ }^{-1}\right)$ and $A L-B r a z e q\left(167 \pm 3.78 \mu \mathrm{g} \mathrm{kg}^{-1}\right)$ contained the least amount of $A A$.

Conclusion: The results indicate that the highest levels of $A A$ are found in the most commonly consumed foods. There was significant difference $(p<0.05)$ in AA levels among different food items and within different brands of the same product.
\end{abstract}

Keywords: Acrylamide, Commercial foods, Traditional foods, Syrian food, Contaminants, UPLCMS/MS

Tropical Journal of Pharmaceutical Research is indexed by Science Citation Index (SciSearch), Scopus International Pharmaceutical Abstract, Chemical Abstracts, Embase, Index Copernicus, EBSCO, African Index Medicus, JournalSeek, Journal Citation Reports/Science Edition, Directory of Open Access Journals (DOAJ), African Journal Online, Bioline International, Open-J-Gate and Pharmacy Abstracts

\section{INTRODUCTION}

The occurrence of elevated levels of acrylamide (AA) in fried and baked carbohydrate-rich foodstuffs was investigated and reported by the Swedish National Food Administration, Stockholm University in 2002 [1]. Based on these findings a series of further investigations were carried out by a number of international organizations, e.g., World Health Organization, and Food and Agriculture Organization of United Nations [2], which detected AA in various foodstuffs. AA has now become a public health concern as it is one of the most common food 
contaminants in processed food at high temperature [3], with neurotoxic carcinogenic and genotoxic effects [5] and classified Group 2A carcinogen [6] and category 2 mutagen. Over the years, efforts have been carried out to build a deeper understanding of AA formation in foodstuff with evidence suggesting that there could be numerous mechanisms by which $A A$ is formed. Among these possibilities is the reaction between free asparagine (Asn) and a carbonyl source resulting in the reduction of sugars (i.e., glucose and fructose) by the Maillard reaction at a high temperature [7], Alternatively, the reaction between acrylic acid and ammonia can form AA in a lipid rich food [8]. Although different analytical techniques such as high-performance liquid chromatography (HPLC), gas chromatography (GC) or liquid chromatography (LC) were successful in the determination of the AA content in food, the ultra-performance liquid chromatography (UPLC) method has the advantage that the resolution is improved with higher analytical sensitivity and a shorter retention time [9].

Various research and quantifications of $A A$ in foodstuffs have been carried out in many countries e.g., Hong Kong [10], North America and European countries [11], Japan. [12], Australian [13], Caribbean countries [14], Spain [15], Poland [16], China [17] and India [18] but until now, only one paper has been published on AA levels in fried potato and falafel from Syria even though Syrians consume considerable amounts of baked and fried traditional foodstuffs. Therefore the main objective of this study was to determine the AA content in various commercial and traditional Syrian foods by a UPLC method and to increase public awareness of the results.

\section{EXPERIMENTAL}

\section{Sampling}

A total of 63 samples were analyzed for toxic AA content. The studies that were carried out on the acrylamide content in food in different countries reported that the main contributing foods are: sweet biscuits $(10-20 \%)$, french fries $(6-46$ $\%)$, coffee $(13-39 \%)$, potato crisps, pastry and potato chips $(16-30 \%)$, and bread and rolls/toasts (10-30 \%) with other food sources contributing less than $10 \%$ of the total exposure [19]. Therefore, according to these data, food sample selection was focused mainly on these products. Likewise, to assess AA levels in traditional foods, a selection of foods that are part of the Syrian diet and that may contain AA were investigated. All food products were purchased from different local supermarkets in the city of Homs, in the Central Western regions of Syria in 2015. All the samples were immediately sealed in polyethylene bags and stored at $4{ }^{\circ} \mathrm{C}$ while the homemade traditional food was prepared according to traditional methods. Each type of food was analyzed in triplicate.

\section{Preparing of traditional food}

AL-Kenafah is a crispy sweet made by using threads of vermicelli and prepared from a white flour mixture. The threads are put on to a metal plate and spread out and then the filling is added which is desalted white cheese. It is then covered with more threads of vermicelli and baked on a flame heater at $180-200{ }^{\circ} \mathrm{C}$ for 10 min. It is sweetened after baking with a heavy sugar syrup, making $40 \%$ of the whole food a sweet crust.

AL-Awamat are small dough balls, which are fried like doughnuts. They are leavened by yeast for 10 min before frying in vegetable oil at 160$180{ }^{\circ} \mathrm{C}$ for 6-8 min. After frying they are sweetened by dipping in heavy sugar syrup.

AL-Namora are composed of fine semolina, sugar and milk, leavened by sodium bicarbonate and baked at $200-250{ }^{\circ} \mathrm{C}$ for $25 \mathrm{~min}$ before sweetening with heavy sugar syrup.

AL-Brazek is a cracker type bakery product consisting of a crust made of white flour, sugar, eggs, butter and some orange juice. It is mixed well and leavened with sodium bicarbonate, covered by sesame and then baked on a flame heater at $180-200{ }^{\circ} \mathrm{C}$ for $15 \mathrm{~min}$.

AL- Mshabak are fried dough sticks made from coarse semolina flour, leavened with yeast and deep fried in vegetable oil at $160-180{ }^{\circ} \mathrm{C}$ for $6-8$ min after which they are sweetened by dipping in a heavy sugar syrup.

\section{Chemicals and standards}

Acrylamide standard (> $99 \%$ ) was purchased from Augsburg, Germany, while 13C3acrylamide (99\% isotopic purity) was obtained from Cambridge Isotope Laboratories Inc. (Andover, USA). Methanol $98 \%$, hexane, potassium hexacyanoferrate and zinc sulfate were obtained from Sinopharm Chemical Reagent Co., Ltd (SCRC) (China). Solid phase extraction cartridges (Oasis MCX and Oasis HLB, $1 \mathrm{~mL}$ ) were supplied by Waters Corp (Berkshire, England). All used solvents were of 
HPLC quality and other used chemicals were of analytical grade.

\section{Standard solutions}

All AA stock and working solutions were prepared in methanol $98 \%$. A standard AA stock solution $(1.0 \mathrm{mg} / \mathrm{mL})$ was prepared by dissolving $1.0 \mathrm{mg}$ of AA in $1.0 \mathrm{~mL}$ of methanol $98 \%$. The stock solutions were diluted with methanol $98 \%$ to give a series of standards $50,100,200,300$, 400, 500, 1000, and $2000 \mathrm{mg} / \mathrm{L}$. All standard solutions were stored in amber narrow-mouth bottles at $48^{\circ} \mathrm{C}$.

Carrez 1 solution was prepared by dissolving 15 $\mathrm{g}$ of potassium hexacyanoferrate in $100 \mathrm{~mL}$ distilled water. Carrez 2 solution was prepared by dissolving $30 \mathrm{~g}$ of zinc sulfate in $100 \mathrm{~mL}$ distilled water.

\section{Sample preparation}

The food samples were ground homogeneously to less than $1 \mathrm{~mm}$ mesh size prior to $A A$ extraction. Ground sample of $1 \mathrm{~g}$ was weighed in a $50 \mathrm{~mL}$ centrifuge tube and defatted by adding hexane and then extracted with $9 \mathrm{~mL}$ of methanol $98 \%$ for 5 min in a vortex mixer whilst $100 \mathrm{uL}$ Carrez I and $100 \mu \mathrm{L}$ Carrez II were added to the centrifuge tubes to precipitate proteins from the co-extractives and then centrifuged at $8000 \mathrm{rpm}$ for $5 \mathrm{~min}$. After centrifugation, the optically clear aqueous extract was transferred to a tube and the solid residue was re-extracted a further two times to increase the extraction yield of AA but without further use of Carrez solution. The combined extracts were evaporated to dryness under a gentle stream of nitrogen $1<3$ psig). The residue was reconstituted in $1 \mathrm{~mL}$ water and eluted through a preconditioned Oasis HLB cartridge at a rate of one drop per second. The first drops of the elute were discarded while the remaining drops were collected and filtered through a $0.22 \mathrm{~mm}$ nylon filter prior to LC-MS analysis.

\section{UPLC MS/MS analysis}

The AA content in a pretreated sample was determined by UPLC-MS/MS with electrospray positive ionization (ESI+). Furthermore, an ACQUITY UPLC quaternary pump system equipped with micro vacuum degasser, thermostated autosampler and thermostated column compartment (Waters, Milford, MA, USA) was coupled with a Micromass Quattro Ultima triple-quadrupole mass spectrometer from Micromass Company Inc. (Manchester, UK). Sample extracts (injection volume: $10 \mu \mathrm{L}$ ) were injected in a UPLC BEH C18 column (Waters, Milford, MA, USA) and the column temperature was set at $25^{\circ} \mathrm{C}$ while the column length was set at $100 \mathrm{~mm}$ with a run time of $3 \mathrm{~min}$ and a flow rate maintained at $0.5 \mathrm{~mL} / \mathrm{min}$. The conditions used for the electrospray source were as follows: source temperature, $120^{\circ} \mathrm{C}$; cone voltage, $35 \mathrm{~V}$; desolvation gas temperature, $350{ }^{\circ} \mathrm{C}$; capillary voltage, $3.5 \mathrm{kV}$; desolvation gas flow, $400 \mathrm{~L} / \mathrm{h}$ nitrogen; cone gas flow, $45 \mathrm{~L} / \mathrm{h}$ nitrogen; argon collision gas pressure to $3 \times 10-3$ mbar for MS/MS. The mobile phase was $10 \%$ methanol $/ 0.1 \%$ formic acid in water with a flow rate of $0.3 \mathrm{~mL} / \mathrm{min}$.

\section{Statistical analysis}

The results are presented as mean \pm standard deviation (SD). The statistical analyses were performed on Statistical Package of Social Sciences (SPSS) version 20 using one way analysis of variance (ANOVA) followed by Dunnett's method to compare the groups. $P \leq$ 0.05 was considered statistically significant.

\section{RESULTS}

\section{Limit of detection (LOD), limit of quantification (LOQ) and recovery}

Recovery of the method was determined by adding different concentrations of $\mathrm{AA}$ to a boiled potato sample followed by the sample extraction steps and UPLC analyses under the same conditions. A percentage recovery of $>90 \%$ was obtained.

\section{Acrylamide content}

A total of 63 commercial food products and traditional foods obtained from Syrian retail stores were analyzed. The median and the range of the AA levels in these products are showed in Table 1 and table 2 showing the first significant variability of AA levels $p \leq 0.05$ among different foodstuffs, including bakery products, potato products, corn products, coffee, and traditional foods. This was also observed within different brands of the same product. Regarding bakery products, the AA levels in bread samples were found to be $153 \pm 2.64 \mathrm{\mu gkg}^{-1}$ in Syrian whole wheat bread and $119 \pm 1.7 \mu \mathrm{gkg}^{-1}$ in Syrian white flour bread. A higher AA content of $263 \pm 3.60$ $\mathrm{\mu gkg}^{-1}$ was found in soft bread while bread sticks and salty bread sticks contained $229 \pm 4.35 \mu \mathrm{g}$ $\mathrm{kg}^{-1}$ and $190 \pm 2.51 \mathrm{\mu gkg}^{-1}$ respectively. Acrylamide levels were detected in the range of $74 \pm 3.64-1433 \pm 2.51 \mu^{-1} \mathrm{gkg}^{-1}$ wheat biscuitrelated products (biscuit and wafer) and) lower

Trop J Pharm Res, June 2016; 15(6): 1277 
Alyousef et al

Table 1: Acrylamide content $\left(\mu \mathrm{g} \mathrm{kg}^{-1}\right)$ of some commercial food products

\begin{tabular}{|c|c|c|c|}
\hline Food group & Acrylamide range & Median & $\begin{array}{l}\text { Number } \\
\text { samples }\end{array}$ \\
\hline Coffee & $64 \pm 3.05-121 \pm 4.58$ & $192^{\mathrm{a}}$ & 44 \\
\hline Corn biscuits, wafers, crackers & $57 \pm 2.64-325 \pm 1.96$ & $160^{\mathrm{b}}$ & 77 \\
\hline Breakfast cereals & $121 \pm 8.73-245 \pm 3.60$ & $167^{\mathrm{c}}$ & 33 \\
\hline Bread & $119 \pm 1.73-263 \pm 3.60$ & $190^{d}$ & 66 \\
\hline Corn chips & $183 \pm 2.64-366 \pm 4.58$ & $249^{\mathrm{e}}$ & 6 \\
\hline $\begin{array}{l}\text { Wheat biscuits, wafers, } \\
\text { crackers, crackers }\end{array}$ & $74 \pm 3.64-1433 \pm 2.51$ & $431^{\top}$ & 10 \\
\hline Potato chips & $396 \pm 3.59-1844 \pm 5.2$ & $1034^{\mathrm{g}}$ & 99 \\
\hline
\end{tabular}

Note: The results are presented as mean \pm standard deviation $(S D)(n=3)$; a-g values are significantly different from each other and significance accepted at $p \leq 0.05$

AA concentrations of $57 \pm 2.64-325 \pm 1.96$ $\mathrm{\mu gkg}^{-1}$ were found in corn biscuit-related products (biscuit and wafer) and $121 \pm 8.73$ $245 \pm 3.60 \mathrm{\mu gg}^{-1}$ in breakfast cereals.

The study showed that the concentrations of $A A$ in different brands of potato products ranged between $396 \pm 3.59$ and $1844 \pm 5.29 \mu^{2} \mathrm{gg}^{-1}$ while in different brands of corn chip products AA content was between $183 \pm 2.64$ and $366 \pm 4.58$ $\mu \mathrm{g} \mathrm{kg}^{-1}$. Regarding traditional foods, the highest levels of AA were found in AL- Mshabak (481 \pm $\left.2.08 \mathrm{\mu gkg}^{-1}\right)$ and AL-Awamat $\left(421 \pm 2.64 \mathrm{\mu gkg}^{-1}\right)$ while the lowest concentrations were detected in AL-Namora $\left(282 \pm 4.35 \mathrm{\mu gkg}^{-1}\right)$ and AL-Kenafa $\left(242 \pm 2.64 \mathrm{\mu gkg}^{-1}\right)$ followed by fried bread (230 $\left.\pm 4.06 \mathrm{\mu gkg}^{-1}\right)$, AL-Fatayer $\left(192 \pm 3.51 \mathrm{\mu gkg}^{-1}\right)$ and AL-Baqlawa (172 $\left.\pm 4.35 \mathrm{\mu gkg}^{-1}\right)$. However, it was also found that the lowest levels of $A A$ were in Eid Aqras $\left(130 \pm 4.58 \mathrm{\mu gkg}^{-1}\right)$, and AL-Brazeq $\left(167 \pm 3.78 \mathrm{\mu gkg}^{-1}\right)$.

Different coffee brands were also analyzed to detect AA content with the results of $113 \pm 2.64-$ $121 \pm 8.73 \mathrm{\mu gkg}^{-1}$ in Medium roasted ground coffee and $64 \pm 3.05-71 \pm 2.33 \mu^{2} \mathrm{gg}^{-1}$ in dark roasted coffee.

\section{Acrylamide levels in traditional Syrian foods}

AA levels in most commonly consumed commercial and home-made traditional Syrian foods are showed in Table 2, including fried and baked products.
The lowest $A A$ contents were detected in Eid Aqras (130 $\left.\pm 4.58 \mu \mathrm{gkg}^{-1}\right)$ and AL-Brazeq (167 \pm $3.78 \mu \mathrm{gkg}^{-1}$ ) where the dough is fermented by yeast for a period of two hours and one hour, respectively.

Table 2: Acrylamide content $\left(\mu \mathrm{gkg}^{-1}\right)$ of traditional foods

\begin{tabular}{|c|c|c|}
\hline $\begin{array}{l}\text { Traditional } \\
\text { Food }\end{array}$ & $\begin{array}{l}\text { AA Median } \\
\left(\mu \mathrm{g} \mathrm{kg}^{-1}\right)\end{array}$ & $\begin{array}{c}\text { No. of } \\
\text { samples }\end{array}$ \\
\hline Eid Aqras & $130 \pm 4.58^{a}$ & 2 \\
\hline Brazeq & $167 \pm 3.78^{b}$ & 2 \\
\hline Baqlawa & $172 \pm 4.35^{\mathrm{b}}$ & 2 \\
\hline Fatayr & $192 \pm 3.51^{\mathrm{c}}$ & 2 \\
\hline Fried bread & $230 \pm 4.06^{\mathrm{d}}$ & 2 \\
\hline Kenafa & $242 \pm 2.64^{e}$ & 2 \\
\hline AL-namora & $282 \pm 4.35^{\top}$ & 2 \\
\hline Awamat & $421 \pm 2.64^{g}$ & 2 \\
\hline Mshabak & $481 \pm 2.08^{n}$ & 2 \\
\hline
\end{tabular}

Note: The results are presented as mean \pm standard deviation ( $S D)(n=3)$; $a-h$ values are significantly different from each other and significance accepted at $p \leq 0.05$

\section{DISCUSSION}

This study focused on Syrian foods available in Syria, such as common commercial food products and some traditional foods. Wheat is the most important staple food commodity in Syria and is consumed primarily as bread, which is mainly composed of wheat flour, salt and water, and leavened using yeast. For the determination of the AA content in wheat products, widely consumed bread types were selected including white wheat bread, whole wheat bread, soft bread, and bread sticks. 
The data showed that the AA content in whole wheat bread was significantly higher $p<0.05$ than $A A$ in bread made with white flour, with the results of $153 \pm 2.64 \mathrm{\mu gkg}^{-1}$ for Syrian whole wheat bread and $119 \pm 1.7 \mu^{-1} \mathrm{gg}^{-1}$ for Syrian white flour bread. This may be due to the difference in AA precursors in bread such as asparagine (Asn) and reducing sugars since whole wheat flour has higher levels of Asn and reducing sugars than white flour [20] thereby leading to more AA formation in these products.

Levels of AA greater than $1000 \mathrm{\mu gkg}^{-1}$ were found in biscuit-related products. The AA concentration range of these products was rather wide $\left(1433 \pm 2.51-57 \pm 2.64 \mu^{2} \mathrm{~kg}^{-1}\right)$, which could be attributed to differences in the recipes and technology, baking temperature and time, and reducing sugars and Asn content. It was demonstrated that ingredients such as almonds and sesame may impact on the AA concentration of bakery products [21].

A previous study showed that the fermentation by yeast decreases the free Asn in raw dough, which resulted in less formation of $A A$ during the baking process; furthermore, prolonged fermentation can lower the AA content by up to $87 \%$ [28]. On the other hand, the highest levels of $A A$ were found in AL-Awamat and ALMshabak $\left(421 \pm 2.64-481 \pm 2.08 \mathrm{\mu gkg}^{-1}\right)$, which are considered to be commonly consumed local fried sweets in Syria, resembling doughnuts; they are leavened by yeast for 10 min and deep fried.

Al-Mshabak dough is prepared from coarse semolina flour while AL-Awamat dough is made from white wheat flour. It was also shown that the AA content in AL-Kenafa $\left(242 \pm 2.64 \mathrm{\mu gkg}^{-1}\right)$ was lower than in AL-Namora (282 \pm 4.35 $\mu \mathrm{gkg}^{-1}$ ) and this could also be related to the differences in the heat treatment, as AL-Kenafah is baked at a lower temperature of $180-200^{\circ} \mathrm{C}$, for a shorter time of $10 \mathrm{~min}$, while the baking temperature and period for AL-Namora is about $200-250^{\circ} \mathrm{C}$ for $25 \mathrm{~min}$.

These differences in product composition and formula are a major factor accounting for differences in the levels of AA precursors; additionally, differences in leavening agents and varieties of processing conditions all play a contributing factor in AA formation in food

This study also showed that the AA content in bakery products that are made with corn flour was lower than those made with wheat flour. These results may support the concept that AA is formed less in corn products than in wheat products [22]. These data were in accordance with those found in previous studies, in which Rufian-Henares et al detected AA levels in commercial biscuits and bread types marketed in Spain and found an AA concentration range of $30-2085 \mu \mathrm{gkg}^{-1}$ for biscuits, $30-151 \mu^{-1} \mathrm{gg}^{-1}$ for crisp bread, $30-296 \mu^{-1} \mathrm{gg}^{-1}$ for crackers and 30 - $323 \mathrm{\mu gkg}^{-1}$ for bread sticks [15]. In another study, AA levels in breakfast cereals were 62 $803 \mu \mathrm{gkg}^{-1}$ [23].

In this study some popular Syrian potato and corn products that are cooked at high temperatures were analyzed to detect toxic $A A$ content, which was reported for the very first time.

The variety of AA levels in the same product samples (396 and $1844 \mathrm{\mu gkg}^{-1}$ in potato products) may be attributable to the various cooking conditions such as temperature, duration of frying, sort of frying oil and the variety of potatoes used, which may contain different amounts of reducing sugars. There are reports suggesting that $A A$ content in food products is affected by different factors relating to differences in the methods of production such as type of frying oil, frying time and temperature [24].

Furthermore the data showed that potato chips contain AA concentrations significantly higher $p \leq$ 0.05 than corn chips (minimum $396 \mu \mathrm{gkg}^{-1}$ for potato products compared to $183 \mathrm{\mu gkg}^{-1}$ for corn, and a maximum of $1844 \mu^{\mu k g g^{-1}}$ compared to 366 $\mu \mathrm{gkg}^{-1}$ ) and this may be due to the potato containing more reduced sugar and Asn amino acid than corn and other cereals. Figure 1 shows AA acrylamide levels in corn and potato chips. Numerous studies have been carried out for AA levels in potato products in different countries. In Iran, the study of AA content in Iranian brands of potato and corn products revealed that the $A A$ levels ranged between $244-1688 \mu \mathrm{gkg}^{-1}$ in potato products and between $30-410 \mu^{-1} \mathrm{~kg}^{-1}$ in corn products [25]. In Austria, the maximum levels of AA in potato crisps was $1500 \mu \mathrm{gkg}^{-1}$ [26], while in Poland the amount of AA in potato crisps was between 352 - $3647 \mathrm{\mu gkg}^{-1}$ depending on the type of crisps [16]. In Japan, AA concentrations in most potato chips and whole potato-based fried snacks were found to be greater than $1000 \mathrm{\mu gkg}^{-1}$ [11].

Like bakery and potato products, different brands of ground coffee were analyzed. The study showed that the AA content varies in coffee powder samples. However, this could be attributed to the differences in the coffee beans 
used for blend ground coffee and also differences in the heat treatments applied during the roasting process with respect to the fact that these parameters are known to play an important role in AA generation in coffee. It was also found that dark roasted coffee powder contained an AA content lower than that of medium roasted coffee meaning that, by virtue of the increase in roasting period and temperatures, there could have been more AA elimination/degradation than AA formation. It has been reported that $A A$ is generated at the beginning of the roasting step and, when it reaches the maximum level, it starts to slowly decrease [27].

\section{CONCLUSION}

This is the first study concerning the determination of $\mathrm{AA}$ content in traditional and common commercial foods in Syria. The study's results provided useful information to add to the AA food database; they also play vital role in the assessment of AA exposure among the Syrian population. These data are almost comparable with studies conducted on AA content originating from different countries e.g., in Asia, the United States, and Europe. In addition, the results agree with previous reports, which indicate that potato products contain a higher content of $\mathrm{AA}$ than corn products, and also confirms that $A A$ concentrations vary according to the food ingredients and the processing conditions.

\section{ACKNOWLEDGEMENT}

This work was supported by the National Science and Technology Program of China (no. 2014BAD33B05). The authors express their thanks to the students of the Nutrition Laboratory of the School of Food Science and Technology at Jiangnan University, China, for their technical assistance.

\section{DECLARATIONS}

\section{Conflict of Interest}

No conflict of interest associated with this work.

\section{Contribution of Authors}

The authors declare that this work was done by the authors named in this article and all liabilities pertaining to claims relating to the content of this article will be borne by them.

\section{REFERENCES}

1. Capuano E, Ferrigno A, Acampa I, Serpen A, Açar ÖÇ, Gökmen $V$, et al. Effect of flour type on Maillard reaction and acrylamide formation during toasting of bread crisp model systems and mitigation strategies. Food Res Int 2009; 42: 1295-1302.

2. FAO/WHO Consultations on the Health Implications of Acrylamide in Food, Report of a Joint FAO/WHO Consultation, Geneva, Switzerland 2002; pp 25-27.

3. Krska R, Becalski A, Braekevelt E, Koerner T, Cao X, -L, Dabeka R, Godefroy S, Lau B, Moisey J, et al. Challenges and trends in the determination of selected chemical contaminants and allergens in food. Anal Bioanal Chem2012; 402: 139-162.

4. ECHA (European Chemicals Agency) Press Release. Acrylamide included in the REACH Candidate List of Substances of Very High Concern for Authorisation. http://echa.europa.eu/doc/press/pr_10_05_acrylamide_ 20100330.pdf. 2010

5. Hogervorst JGF, Baars B-J, Schouten LJ, Konings EJM, Goldbohm RA, van den Brandt PA. The carcinogenicity of dietary acrylamide intake: $A$ comparative discussion of epidemiological and experimental animal research. Crit Rev Toxicol 2010; 40: 485-512.

6. IARC. Monographs on the evaluation of carcinogenic risks to humans, 1994; 60, 389.

7. Tareke E, Rydberg P, Karlsson P, Eriksson S, Tornqvist M. Analysis of acrylamide, a carcinogen formed in heated foodstuffs. J Agr Food Chem 2002; 50: 49985006.

8. Yaylayan VA, Wnorowski A, Locas CP. Why asparagine needs carbohydrates to generate acrylamide. J Agr Food Chem 2003; 51: 1753-1757.

9. Zhang Y, Jiao J a, Cai Z, Zhang Y, Ren Y. An improved method validation for rapid determination of acrylamide in foods by ultra-performance liquid chromatography combined with tandem mass spectrometry. J. Chromatogr. A 2007; 1142: 194-198.

10. Leung KS, Lin A, Tsang CK and Yeung ST. Acrylamide in Asian foods in Hong Kong. Food Addit Contam 2003; 20: 1105-1113.

11. FDA (Food and Drug Administration). 2005. Exploratory data on acrylamide in food. Available: http://www.cfsan.fda.gov/ dms/acrydata.html. Accessed 2006 January 24.

12. Yoshida $M$, Ono $H$, Chuda $Y$, Yada, $H$, OnhishiKameyama, M, Kobayashi $H$, et al. Acrylamide in Japanese processed foods and factors affecting acrylamide level in potato chips and tea. Adv Exp Med Biol 2005; 561: 405-413.

13. Croft $M$, Tong $P$, Fuentes $D$ and Hambridge T. Australian survey of acrylamide in carbohydrate-based foods. Food Addit Contam, 2004; 21: 721-736.

14. Bent GA, Maragh P, Dasgupta T. Acrylamide in Caribbean foods - residual levels and their relation to reducing sugar and asparagine content. Food Chem 2012; 133: 451-457.

Trop J Pharm Res, June 2016; 15(6): 1280 
15. Rufian-Henares JA, Arribas-Lorenzo G, Morales FJ. Acrylamide content of selected Spanish foods: survey of biscuits and bread derivatives. Food Addit Contam 2007; 24:343-350.

16. Mojska H, Gielecińska I, Szponar L, OHarzewski M. Estimation of the dietary acrylamide exposure of the Polish population. Food Chem Toxicol 2010; 48: 20902096.

17. Yang $L X$, Zhang GX, Yang $L X$, He Y. LC-MS/MS determination of acrylamide in instant noodles from supermarkets in the Hebei province of China. Food Addit Contam Part B Surveill 2012; 5: 100-104.

18. Shamla L, Nisha P. Acrylamide in deep-fried snacks of India. Food Addit Contam Part B Surveill. 2014; 7: 220225.

19. JECFA. (2005). Joint FAO/WHO expert committee on food additives: Sixty-fourth meeting. http://www.who.int/ foodsafety/chem/en/.

20. Hamlet $C$, Sadd $P$, \& Liang L. Material variability: $A$ tool to minimize acrylamide formation in baked cereal products? (AGFD 251) In: 234th ACS Meeting, Boston MA, August 19-23, 2007, Washington, DC: ACS.

21. Mustafa A, Andersson $R$, Kamal-Eldin A, Åman $P$. Fortification with Free Amino Acids Affects Acrylamide Content in Yeast Leavened Bread. In: Victor Preedy, editor. Flour and Breads and their Fortification in Health and Disease Prevention.1st ed. London: Elsevier Inc; 2011. p. 325-335.
22. Stadler, $R H$. The formation of acrylamide in cereal products and coffee, In "Acrylamide and other hazardous compounds in heat-treated foods," K. Skog and J. Alexander (Eds), Woodhead Publishing, Cambridge, UK, Chapt. 2, 2006; pp 23-40.

23. Bermudo E, Moyano E, Puignou L, Galceran MT. Liquid chromatography coupled to tandem mass spectrometry for the analysis of acrylamide in typical Spanish products. Talanta 2008 76: 389-394.

24. Ozkaynak E, Ova G. Effects of various cooking conditions on acrylamide formation in rolled patty. Food Addit. Contam 2009; 26: 793-799.

25. Boroushaki MT, Nikkhah E, Kazemi A, Oskooei M, Raters M. Determination of acrylamide level in popular Iranian brands of potato and corn products. Food Chem Technol 2010; 48: 2581-2584.

26. Murkovic M. Acrylamide in Austrian foods. J Biochem Biophys Meth 2004; 61: 161-167.

27. Hamide ZS, \& Gokmen V. Study of acrylamide in coffee using an improved liquid chromatography mass spectrometry method: Investigation of colour changes and acrylamide formation in coffee during roasting. Food Addit Contam 2005; 22: 214-220.

28. Fredriksson $H$, Tallving $J$, Rosén $J$, Áman $P$. Fermentation Reduces Free Asparagine in Dough and Acrylamide Content in Bread. Cereal Chem 2004; 81(5): 650-653. 